\title{
Embryonal Tumor with Multilayered Rosettes, Not Otherwise Specified
}

National Cancer Institute

\section{Source}

National Cancer Institute. Embryonal Tumor with Multilayered Rosettes, Not Otherwise

Specified. NCl Thesaurus. Code C129499.

A central nervous system embryonal neoplasm characterized by the presence of histological features consistent with embryonal tumor with multilayered rosettes and absence of C19MC amplification. 